increasing millions of Asian internet users, even in developing nations. Vietnam's usage grew by 10,882 percent last decade and it looks as though India's usage is set to explode with half of its 1.16 billion people under 25 years of age; a relatively small 16.18 million internet users is going to multiply rapidly in a short time. The research highlights governments are clearly aware of the impact of technology on the dissemination of information. Cambodia's Ministry of Information spokesman is quoted: 'Personal interaction and direct contact with voters will ultimately determine the choices and responses of voters.' Yet others like Vietnam see the need to curtail. Human Rights Watch in 2010 observed that the Government detained bloggers while permitting cyber attacks against anti-government pages. Stephen Quinn's article quotes Vietnam's Prime Minister Nguyûn Tân Dŭng: "The truth is always the truth but we must choose the suitable time to tell the truth to ensure the country's interests.' While the reports provide excellent case studies, many questions remain, such as how deep is the effect on political results? And is it really a revolution in itself or simply an ever-adapting medium? -Alex Perrottet is Pacific Media Watch's contributing editor.

\section{How to be a mojo in Asia}

Mojo-mobile journalism in the Asian region, by Stephen Quinn. Singapore: Konrad Adenauer Stiftung: 2009. 66 pp. No ISBN. E-book at www.kas.de/wf/doc/ kas_18599-544-1-30.pdf

TEPHEN QUINN presents in
this rather concise publication the concept of mobile journalism (mojo) within the Asian context. Along with practical tips on how to be a mojo in this region, Quinn provides cases studies and examples in an anecdotal form from Asia and around the world to support his argument that journalists in Asia need to embrace new technologies and learn how to maximise the use of mobile phones to improve and increase their mobility. The author links his argument for mobile journalism with the rapid growth of mobile and internet use in Asia which contributes not only to further technological advancements in this area but also to an increased demand for more and 'fresher' news. All journalists are potential mojos, although not all will engage with this form of journalism. This approach is more appropriate for the first level of reporting, breaking news. A mojo, according to Quinn, uses a mobile phone to gather and distribute news which can consist of text, audio, stills or video or a combination. 


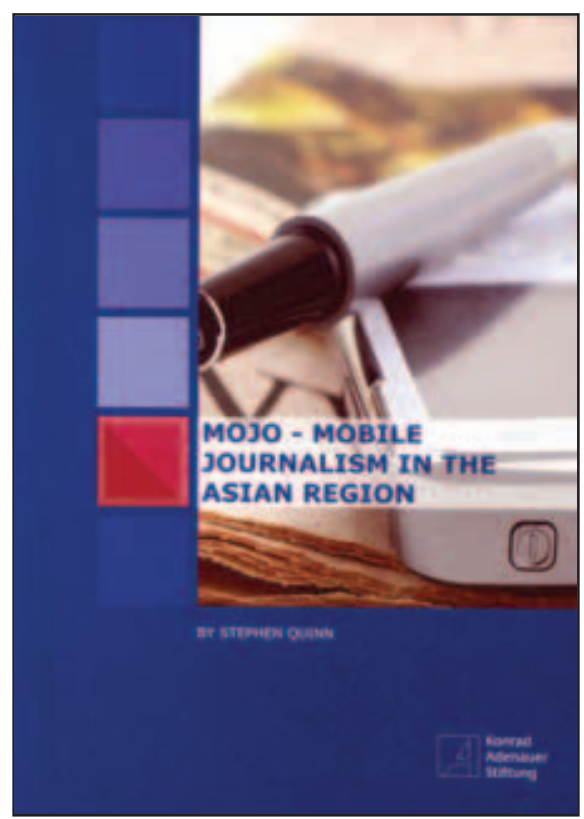

Mojos tend to work alone, in comparison to video journalists for instance who tend to operate in a small team. Mobile technology allows the mojo journalist to operate thus in a more discreet and faster way. The book is organised around five small chapters, outlining what mobile journalism is, how to be a mobile journalist, techniques of mojo reporting and how to address workflows issues. There is undoubtedly a need for new newsroom structures that are relevant for knowledge-age workforces and Quinn provides here suggestions that best support mojo journalism. Ethical and privacy issues are very briefly touched. As the author says, codes of ethics vary enormously in the Asian region which makes it very difficult to provide overall guidelines.-Dr Evangelia Papoutsaki is associate professor in communication studies at Unitec, Auckland.

\section{Vital media resource}

\section{Routledge Companion to News and Journalism, edited by Stuart Allan.} London: Routledge, 2010. 642 pp. ISBN 9780-415-46529-8

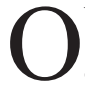
VER the past two decades, all aspects of media-communication have been reshaped by economic, technological and social forces. It is difficult to track these multiple changes and to evaluate their general significance. All sub-fields of media-communication research contain burgeoning literatures in need of conceptual and empirical classification. Major publishers are rapidly addressing this situation.

Wiley-Blackwell, for example, have recently produced handbooks in the fields of Global Communication, Global Communication and Media Ethics, Internet Studies, Intercultural Communication, Media Audiences and the Political Economy of Communication. The Routledge Companion of News and Journalism is a welcome addition to this genre. Editor Stuart Allan has done remarkably well to arrange 56 chapters and 